\title{
Gas turbine prime movers fuelled by LNG as a future alternative for sustainable power in marine propulsion: current emission policy assessment and exhaust quality evaluation
}

\author{
Dario Barsi ${ }^{1 *}$, Andrea Bono $^{1}$, Francesca Satta $^{1}$ and Pietro Zunino ${ }^{1}$ \\ ${ }^{1}$ University of Genoa, DIME, via Montallegro 1, 16145 Genoa, Italy; dario.barsi@unige.it, \\ andrea.bono@edu.unige.it, francesca.satta@unige.it, pietro.zunino@unige.it
}

\begin{abstract}
In recent years, climate change has dramatically shown its effects in terms of fluctuations of temperatures because of increased global warming due to greenhouse gas emissions. Pollution control is strongly linked to atmospheric acidification and contaminants in combustion exhausts. In such a contest, marine propulsion is actually a key player that is accounting for a substantial contribution to pollution. Kyoto protocol's obligations established decarbonisation as a compulsory commitment and contaminant constraints are defined by current emission policy and regulations both on a global and on a regional basis. In this paper, a study is carried out in order to develop a framework for current emission policy and assessment of exhausts due to constraints imposed on fuel choice. Gas fuelled marine propulsion, implemented through state-of-the-art GT areoderivative prime movers, powered by LNG, is analysed from the environmental point of view. The pollutant emissions from various size GT models are evaluated through both GT datasheets and commercial (as well as self-coded) software, in order to assess the validity of LNG as an alternative fuel option for future sustainable marine applications.
\end{abstract}

\section{Introduction}

Greenhouse gas emissions (GHG) are being recently considered responsible for an undisputable trend in global warming, Thus, pollution control is usually strongly recommended and lately established by law.

The transport sector is a key player for such a problem: its powering is one of the energy conversion processes responsible for the above pollutant injections into the atmosphere and its contribution is dependent on conventional fuels. In the transport sector, marine propulsion is certainly accounting for a substantial contribution to pollution, especially in coastal zones, main marine routes, and harbour towns, as well as in a global world framework relating to sustainable energy policies. For this reason, marine propulsion is considered a keystone to sustainable power generation and innovative systems.

\footnotetext{
* Corresponding author: dario.barsi@unige.it; tel.: +39 0103532550
} 
Reduction of $\mathrm{CO}_{2}$ from combustion is established by Kyoto protocol's obligations: decarbonisation may be met by gradually substituting traditional fuels (diesel and variableweight marine gas oils) with alternative fuels marked out by a more propitious hydrogen-tocarbon ratio (natural gas). Contaminant constraints are established by current emission policy and regulations issued on a global and on a regional basis. For these reasons, abatement needs are actually forcing naval companies to consider either fuel substitution or the installation on board of expensive, as well as heavy, abatement device equipment. Gas fuelled propulsion can be implemented through GT prime movers, whose elected fuel for marine applications shows LNG (Liquified Natural Gas) to be one of the best candidate in a naval context [1].

In this paper a study is carried out in order to develop a framework for current emission policy and assessment of exhausts. The regulatory policy for emission control is discussed and its impact is taken into account. Since intercontinental naval routes span different geographical regions, focus is got on the legislative context and its evolution with regard to standards and regulations on a global basis. Emissions from different GT models are evaluated through GT manufacturer's datasheets and simulated by commercial as well as self-coded software, in order to assess the validity of LNG as a sustainable alternative fuel option for marine propulsion.

\section{Marine propulsion}

Marine propulsion has been generally characterized by large internal combustion engines ( 2 strokes/4 strokes slow/medium speed diesel), powered by MGO (marine gas oil), MDO (marine diesel oil), IFO (intermediate fuel oil), HFO (heavy fuel oil), as common fuelling resources. Recently, due to environmental attention, a new interest has been aroused for innovative fuel sources, such as natural gas and liquefied gas (gas-fuelled engines). Similarly, interest has been aroused towards innovative propulsion systems, such as combined gas/steam cycles: COGAS (combined gas and steam), where propulsion is directly driven by the turbine shaft, and COGES (combined gas turbine electric and steam), where propulsion is driven by electrical power generated by the turbine shaft. For these systems GTs are ideal innovative prime movers $[1,2,3,4]$.

As compared with the Diesel counterpart, the gas turbine, which is characterized by smaller spaces for the engine and auxiliaries (especially for a power range above 20-30 MW [5]), reduced vibrations, and greater speed in the loading variation, nevertheless, it involves a higher cost on fuel and a lower efficiency. It is, however, appreciated above all for its reliability and reduced maintenance needs, both in terms of personnel and time required [6]. The first applications on commercial ships for freight and passenger transport date back to the 1970s with the GTS Finnjet [7]. Generally, a gas turbine requires about 50\% less auxiliary equipment than a traditional ship engine and $75 \%$ less space on board once installed, including the engine and auxiliaries [2]. Maintenance is lowered to a maximum of 24 hours $[2,6,8]$ using specific diagnostic software. In order to overcome the drawbacks associated with the lower efficiencies, as compared with the low speed Diesel engines actually installed on board, gas/steam combined cycle layouts, widely adopted in terrestrial applications, are in the last years being considered also for naval applications. The use of combined gas/steam cycles (in the aforementioned COGAS or COGES arrangements) allows on the one hand to exploit the advantages associated with the gas turbines just listed and on the other to maximize the efficiency of the plant thanks to the heat recovery from exhausts [1].

\section{Environmental framework}

Naval transport is accounting for $5-10 \%$ of anthropic world $\mathrm{SO}_{2}$ emissions [9] and for 80 times the $\mathrm{SO}_{\mathrm{X}}$ amount out of the aviation transport [10]. So a limiting regulation will obviously impact on cost increase for new designed ships (from $20 \%$ to $85 \%$, depending on 
speed, fuel price and ship tonnage) [11]. A similar consideration is valid for any different regulated pollutant.

IMO regulations have identified multiple international controlled areas (tab. 1). Harder constraints may be present on a regional or on a local basis (such as EC regulations [12] and related discretion in establishing additional limit values left to EC member states).

Table 1. Currently IMO controlled areas.

\begin{tabular}{llll}
\hline Geographical zone & Pollutant & Adoption & In force \\
\hline Caribbean Sea (USA) & $\mathrm{NO}_{\mathrm{X}}, \mathrm{SO}_{\mathrm{X}}, \mathrm{PM}$ & $26 / 07 / 11$ & $01 / 01 / 14$ \\
North America & $\mathrm{NO}_{\mathrm{X}}, \mathrm{SO}_{\mathrm{X}}, \mathrm{PM}$ & $23 / 03 / 10$ & $01 / 08 / 12$ \\
North Sea & $\mathrm{SO}_{\mathrm{X}}$ & $22 / 05 / 05$ & $22 / 11 / 07$ \\
Baltic Sea & $\mathrm{SO}_{\mathrm{X}}$ & $26 / 09 / 97$ & $19 / 05 / 06$ \\
\hline
\end{tabular}

MARPOL Convention 73/78 has been an international panel aimed at reducing marine pollution originated from both ordinary ship operations and ship extreme events (e.g. hydrocarbon leakage to sea). Annex VI of MARPOL Convention (resolution of 1997, in force since 2005) concerns air pollution. It is applied to ships whose flag-country ratified the 1997 agreement as well as to ships whose flag-country did not, but that are anyhow operating into adherent countries' seas. Annex VI concerns 1) $\mathrm{NO}_{\mathrm{X}}$ and $\mathrm{SO}_{\mathrm{X}}$ in exhausts from internal combustion engines; 2) Volatile Organic Compound (VOC) out of shipload zone of cargo tanks. Regulation 13 of Annex VI is relevant to $\mathrm{NO}_{\mathrm{x}}$ emissions, Regulation 14 is relevant to $\mathrm{SO}_{\mathrm{X}}$ emissions. Details will be discussed in the following sections.

\section{Emission regulation}

\section{1 $\mathrm{NO}_{\mathrm{x}}$ emissions}

Annex VI (Reg. 13) [13] from MARPOL Convention 73/78 and $N O_{X}$ Technical Code [14] are regulations governing test, certification and control over $\mathrm{NO}_{\mathrm{X}}$ emissions from ordinary ship propulsion powered by internal combustion engines. $\mathrm{NO}_{\mathrm{X}}$ emission values are stated increasingly over years (application periods are called Tiers) for ships built from 2000, 2011 and 2016 (tab. 2). Since 01/01/16 all new built ships must comply with Tier III (3,4 - 2,0 $\mathrm{g} / \mathrm{kWh} \mathrm{NO}_{\mathrm{X}}$ limit).

Reg. 13 - part. 1 [13] deals with engines above the $130 \mathrm{~kW}$ level and a distinction is drawn between an engine built before 2000 and after 2000. The latter must grant reduced emissions compared with the former one. NECA areas $\left(\mathrm{NO}_{X}\right.$ Emission Control Areas) are established, where $\mathrm{NO}_{\mathrm{X}}$ emission values must drop below 3,4 - 2,0 $\mathrm{g} / \mathrm{kWh}$, starting from January 2016. Reg. 13 - part. 2 [13] specifically deals with engines built before 2000 (1/1/90-31/12/99) exceeding the $5000 \mathrm{~kW}$ level. Tier $I$ is in such a case applied when the engine matches additional environmental certification and technical-economical features.

As of today, a ship built after 01/01/16 must comply with Tier III: 1) 3,4 $\mathrm{gNO}_{\mathrm{X}} / \mathrm{kWh}$ (engine speed lower than $130 \mathrm{rpm}$ ); 2) $9 \cdot \mathrm{n}^{-0,2} \mathrm{gNO}_{\mathrm{X}} / \mathrm{kWh}$ (engine speed ranging between 130-2000 rpm); 3) 2,0 $\mathrm{gNO}_{\mathrm{X}} / \mathrm{kWh}$ (engine speed higher than $2000 \mathrm{rpm}$ ) (tab. 3).

Table 2. Application cases.

\begin{tabular}{lll}
\hline Engine type & Power & Commentary \\
\hline Any diesel & $\geq 130 \mathrm{~kW}$ & Ship built on or after $01 / 01 / 2000$ \\
Any diesel & $\geq 130 \mathrm{~kW}$ & Engine subject to important reconversion at $01 / 01 / 2000$ \\
\hline Tiers & & \\
\hline Tier I & & Engine powering a ship built on or after $01 / 01 / 00$ \\
Tier II & & Engine powering a ship built on or after $01 / 01 / 11$ \\
Tier III & & Engine powering a ship built on or after $01 / 01 / 16$ \\
\hline
\end{tabular}


Table 3. $\mathrm{NO}_{\mathrm{X}}$ emission limits.

\begin{tabular}{lllll}
\hline Tier & Ship building & Limit $[\mathbf{g} / \mathbf{k W h}]$ & Limit $[\mathbf{g} / \mathbf{k W h}]$ & $\begin{array}{l}\text { Limit }[\mathbf{g} / \mathbf{k W h}] \\
\mathbf{n} \leq \mathbf{1 3 0}\end{array}$ \\
& & $\mathbf{1 3 0}<\mathbf{n}<\mathbf{2 0 0 0}$ & $\mathbf{n} \geq \mathbf{2 0 0 0}$ \\
\hline I & $01 / 01 / 00$ & 17,0 & $45 \cdot \mathrm{n}^{-0,2}$ & 9,8 \\
II & $01 / 01 / 11$ & 14,4 & $44 \cdot \mathrm{n}^{-0,23}$ & 7,7 \\
III & $01 / 01 / 16$ & 3,4 & $9 \cdot \mathrm{n}^{-0,2}$ & 2,0 \\
\hline
\end{tabular}

\subsection{SOx emissions}

Geographical areas subjected to $\mathrm{SO}_{\mathrm{X}}$ emission control are listed in Annex VI (Reg. 14), Annex I (Reg. 1), Annex V (Reg. 1) [13] of MARPOL Convention 73/78. Those areas are included in geographical zones reported in tab. 1 .

Annex VI introduces limitations to the sulphur content allowed for the marine fuel (tab. 4): 1) a global limit has been established (sulphur content from $4,50 \%$ to $3,50 \%$, in force since 2012 , with an additional drop to $0,50 \%$ by 2020 and again a further undefined drop is scheduled by 2025); 2) a specific limit for SECA areas (Sulphur Emission Control Areas), where limitations are even far demanding (sulphur content is set at 1,00\% as of 2012 and at $0,10 \%$ as of 2020$)$.

Table 4. Fuel sulphur content.

\begin{tabular}{llll}
\hline \multicolumn{2}{l}{ Outside SECA areas } & \multicolumn{2}{c}{ SECA areas } \\
\hline $\begin{array}{l}\text { Sulphur content } \\
{[\% \mathbf{m} / \mathbf{m}]}\end{array}$ & Time range & $\begin{array}{l}\text { Sulphur content } \\
{[\mathbf{\%} \mathbf{m} / \mathbf{m}]}\end{array}$ & Time range \\
\hline 4,50 & before $01 / 01 / 12$ & 1,50 & before $01 / 07 / 10$ \\
3,50 & from $01 / 01 / 12$ to $31 / 12 / 19$ & 1,00 & from $01 / 07 / 10$ to $01 / 01 / 15$ \\
0,50 & from $01 / 01 / 20$ & 0,10 & from $01 / 01 / 15$ \\
\hline
\end{tabular}

According to Annex VI, ships inside a SECA area must comply with one of the following: 1) fuel sulphur content is lower than $1,5 \% \mathrm{~m} / \mathrm{m} ; 2$ ) an exhaust scrubbing system maybe alternatively employed, providing at least a $6,0 \mathrm{gSOx} / \mathrm{kWh}$ abatement limit; 3 ) an alternative technological system, capable of granting a similar abatement, is at any rate employed.

As the rule concerns sulphur content inside the fuel, in order to match sulphur content inside the exhaust to appropriate values, IMO has introduced a simplified procedure [15]. The sulphur content is verified on the exhausts and an emission ratio is calculated. A comparison table has been regressively issued to match the calculated emission ratio against an equivalent deduced sulphur content in the fuel. A subsequent update [16] ratifies the existing limitations and specifies conditions in order to equivalently match Annex VI Reg. 14.1 and Reg. 14.4 (tab. 5) [16].

Table 5. Tab. 1 from Resolution MEPC. 259 (68) [16].

\begin{tabular}{cc}
\hline $\begin{array}{c}\text { Marine fuel sulphur content } \\
{[\mathbf{\%} \mathbf{~ m} / \mathbf{m}]}\end{array}$ & $\begin{array}{c}\text { Emission ratio } \\
\left.\mathbf{S O}_{\mathbf{2}} \mathbf{( p p m )} / \mathbf{C O}_{\mathbf{2}} \mathbf{[ \%} \mathbf{~ v} / \mathbf{v}\right]\end{array}$ \\
\hline 4,50 & 195,0 \\
3,50 & 151,7 \\
1,50 & 65,0 \\
1,00 & 43,3 \\
0,50 & 21,7 \\
0,10 & 4,3 \\
\hline
\end{tabular}

Reg. 14, due to its stringent limitations, let adherent states to allow on their territory the use of technologies and fuels able to meet Annex VI requirements. EC regulations [12] are similarly promoting both the usage of a fuel whose sulphur content is within approved limits, as well as any alternative technology substituting approvable on-limit fuels. 


\subsection{CO emissions}

At the best knowledge of the authors, IMO has never issued any international CO emission regulation. National regulations, such as U.S. EPA's directives, may represent a valid reference [17]. EPA's Tiers II set $\mathrm{CO}$ emission at a 5,0 $\mathrm{gCO} / \mathrm{kWh}$ limit for large marine engines.

\section{4 $\mathrm{CO}_{2}$ emissions}

$\mathrm{CO}_{2}$ emissions are not subject to established limits yet, however they will be in the next future. IMO has introduced an Energy Efficiency Design Index (EEDI) [18], applied to the vessel design phase, and an Energy Efficiency Operational Indicator (EEOI) [19], applied to the vessel operational life. Those indexes give information about the ratio of environmental costs over social benefits and efficiency performance over time, during day-to-day vessel operations.

In the EC framework, $\mathrm{CO}_{2}$ quotas authorization in the naval sector [20,21] has recently became an obligation, hence $\mathrm{CO}_{2}$ emission evaluation is progressively affecting the marine sector.

\section{Propulsion and fuel characteristics for the study}

For the present study three GTs have been selected as possible candidate prime movers and on board service power engines for marine applications, to empower COGES propulsion technology, through gas/steam combined cycles, with particular reference to intercontinental cruise shipping. GTs' technical specs are reported in tab. 6 from the vendor datasheets at ISO conditions $[22,23,24]$. All models are not intended to use steam or water injection for $\mathrm{NO}_{\mathrm{X}}$ mitigation.

Table 6. GT prime movers.

\begin{tabular}{lllllllll}
\hline GT Model & $\begin{array}{l}\text { Power } \\
\text { Output }\end{array}$ & Heat Rate & $\begin{array}{l}\text { Pressure } \\
\text { Ratio }\end{array}$ & RPM & $\begin{array}{l}\text { Exh. } \\
\text { Flow }\end{array}$ & $\begin{array}{l}\text { Exh. } \\
\text { Temp. }\end{array}$ & NO $_{\mathbf{x}}$ & CO \\
& {$[\mathbf{M W}]$} & {$[\mathbf{k J} / \mathbf{k W h}]$} & & & {$[\mathbf{k g} / \mathbf{s}]$} & {$\left[{ }^{\circ} \mathbf{C}\right]$} & $\begin{array}{l}\text { [ppm } \\
\left.\mathbf{1 5 \%} \mathbf{O}_{2}\right]\end{array}$ & $\begin{array}{l}{[\mathbf{p p m}} \\
\left.\mathbf{1 5 \%} \mathbf{O}_{2}\right]\end{array}$ \\
\hline GE LM2500+ & 31,0 & 9796 & 22,8 & 3600 & 89.4 & 486 & 25 & 25 \\
Siemens SGT A30 & 27,2 & 9904 & 20,6 & 3600 & 90.1 & 501 & 25 & 25 \\
Solar Taurus 70 & 8,2 & 10470 & 16,5 & 3600 & 26,4 & 515 & 9 & 15 \\
\hline
\end{tabular}

Depending on geographical extraction gas fields, LNG shows large composition variability. Simulations have been based on LNG mean composition (3 mixtures) from literature $[4,25]$ and sulphur contaminant tolerance from regulations [26, 27, 28], as reported in tabs. 7 and 8 . The maximum sulphur value has been precautionarily adopted to test performance against the most unfavourable conditions (100 ppm - 0,01\% vol).

Table 7. LNG mixture composition.

\begin{tabular}{|c|c|c|c|c|c|c|c|}
\hline Mixture & $\mathrm{CH}_{4}$ & $\mathrm{C}_{2} \mathrm{H}_{6}$ & $\mathrm{C}_{3} \mathrm{H}_{8}$ & $\mathrm{C}_{4} \mathrm{H}_{10}$ & $\mathrm{C}_{5} \mathrm{H}_{12}$ & $\mathrm{C}_{6} \mathrm{H}_{14}$ & $\mathbf{N}_{2}$ \\
\hline & [\% vol] & [\% vol] & [\% vol] & [\% vol] & [\% vol] & [\% vol] & [\% vol] \\
\hline LNG light & 98,60 & 1,18 & 0,10 & 0,02 & 0,00 & 0,00 & 0,10 \\
\hline LNG medium & 92,30 & 5,00 & 1,50 & 0,60 & 0,10 & 0,00 & 0,50 \\
\hline LNG heavy & 85,87 & 8,40 & 3,00 & 1,20 & 0,23 & 0,00 & 0,50 \\
\hline
\end{tabular}

Table 8. LNG sulphur tolerance.

\begin{tabular}{llll}
\hline Contaminant & $\begin{array}{l}\text { EASEE } \\
\text { gas specs }\end{array}$ & $\begin{array}{l}\text { ISO } \\
\mathbf{1 5 4 0 3 : 2 0 0 6}\end{array}$ & OLT S.p.A. \\
\hline & {$\left[\mathbf{m g} / \mathbf{S m}^{\mathbf{3}}\right]$} & {$\left[\mathbf{m g} / \mathbf{S m}^{\mathbf{3}}\right]$} & {$\left[\mathbf{m g} / \mathbf{S m}^{\mathbf{3}}\right]$} \\
\hline $\mathrm{RSH}$ & 6 & 15 & 15,5 \\
$\mathrm{H}_{2} \mathrm{~S}$ & 5 & 5 & 6,6 \\
$\mathrm{~S}$ & 30 & 120 & 150 \\
\hline
\end{tabular}




\section{Results}

\subsection{Methodology}

GTs have been simulated through the THERMOFLEX ${ }^{\circledR}$ process-scheme design environment, granting full control (on fuel and air properties, GT engine, etc.). The fuel flow and the outlet temperature are calculated on the assumption that the fuel is oxidized in full measure and its lower heating value is fully exploited to produce the combustor exit temperature.

Emissions of $\mathrm{CO}_{2}$ and of $\mathrm{SO}_{\mathrm{X}}$ are estimated on the assumption that all of the fuel's consumed carbon and sulphur are fully oxidized. Other pollutants $\left(\mathrm{CO}, \mathrm{NO}_{\mathrm{X}}\right)$ in the exhaust are estimated through data from manufacturers' datasheets or through the procedure hereafter described.

Closed mass and chemical balances around the gas turbine are therefore calculated, as well as exhaust composition and enthalpy, providing the core quantities required for an overall heat balance check.

\subsection{Discussion}

The performance of the three selected gas turbines has been simulated under design and offdesign conditions, through THERMOFLEX ${ }^{\circledR}$ by Thermoflow Inc [29]. $\mathrm{SO}_{\mathrm{X}}$ and $\mathrm{CO}$ emissions have been directly taken as a result of the Thermoflex simulations.

$\mathrm{SO}_{\mathrm{X}}$ emissions, plotted below in the shape of $\mathrm{SO}_{2}$ emission ratio, as prescribed by the regulations, show an appreciable dependence on LNG composition and a quite constant trend with GT load. They are, however, way beyond the $4,3 \mathrm{SO}_{2}(\mathrm{ppm}) / \mathrm{CO}_{2}[\% \mathrm{v} / \mathrm{v}]$ indicating a fuel sulphur content lower than $0,10 \% \mathrm{~m} / \mathrm{m}$ (fig. 1).
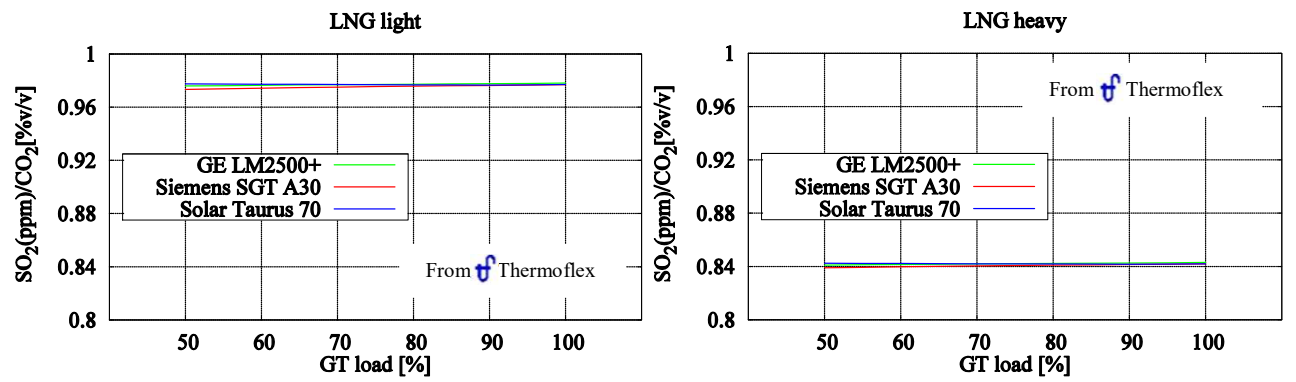

Fig. 1. SOX emissions from GTs for LNG light (on the left) and LNG heavy (on the right).

CO emissions show poor dependence on LNG composition. The value is way beyond the limit of 5,0 g/kWh stated by EPA Tier II (fig. 2).

LNG light

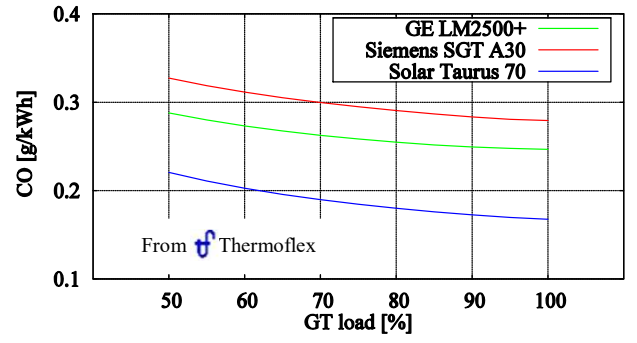

LNG heavy

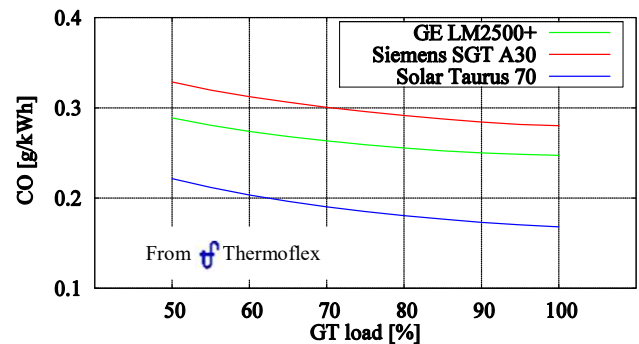

Fig. 2. CO emissions from GTs for LNG light (on the left) and LNG heavy (on the right). 
For the above reported cases, results concerning LNG medium mixture, here not plotted for brevity, always show an intermediate trend between LNG light and LNG heavy mixtures.

To evaluate the thermal $\mathrm{NO}_{\mathrm{X}}$ emissions, a different procedure, based on the classical theory, has been followed. This calculation, being simplified, has some limitations, based above all on the impossibility of using fuel mixtures. For this reason, pure methane has been simulated, which is a viable approximation for all three LNG mixtures. The calculation involves two phases. A first step consists in determining the adiabatic flame temperature and the concentration of the combustion products at equilibrium, once known the chemical composition of the fuel and the equivalence ratio. The calculation model is based on the use of the codes provided by Turns [30], based in turn on the routine of Olikara \& Borman [31]. During the second phase, the values calculated at the previous step are used as input to determine the $\mathrm{NO}_{\mathrm{X}}$ emissions, according to the extended Zeldovich mechanism [32]. The limitation of this procedures is related to the possibility of evaluating only thermal $\mathrm{NO}_{\mathrm{x}}$ formation mechanism, related to adiabatic flame temperature value, which strongly reduces for partial load conditions. However, since usually in gas turbines the contribution from other (prompt and $\mathrm{N}_{2} \mathrm{O}$ intermediate) formation mechanisms represent the $5-10 \%$ of the total amount of NOx production, the neglected contributions should be small.

The result of the calculation for the different off-design conditions is shown both in terms of ppm made non dimensional by the value obtained under on-design conditions (fig. 3, on the left), and in terms of $\mathrm{gNO}_{\mathrm{X}} / \mathrm{kWh}$ (fig. 3, on the right), to allow the comparison with the limits imposed by regulations. The $\mathrm{NO}_{\mathrm{X}}$ value is way beyond the limit of $2,0 \mathrm{~g} / \mathrm{kWh}$ stated by EPA Tier III, for all of the operating conditions.
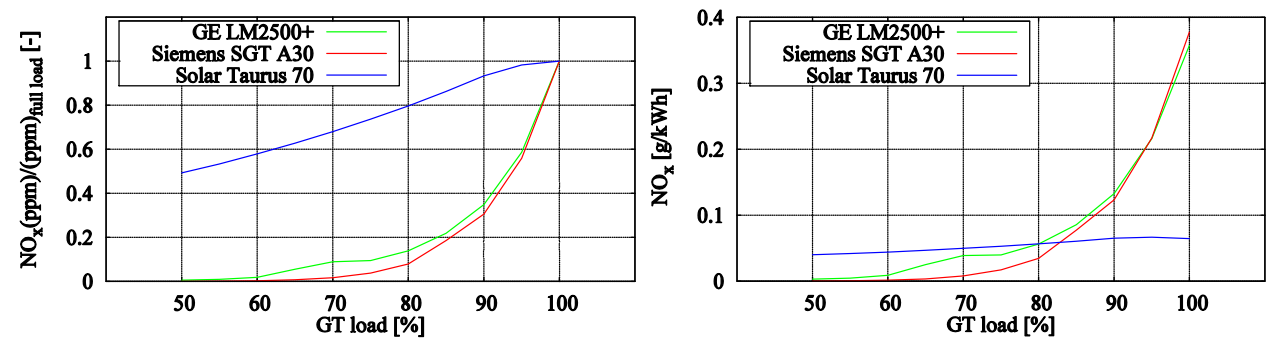

Fig. 3. Thermal $\mathrm{NO}_{\mathrm{x}}$ emissions from GTs for LNG light

As no $\mathrm{CO}_{2}$ regulation at present forces the establishing of compulsory values (see Section 4.4), this emission component is not relevant from any existing emission regulation compliance. Anyway, for completeness a comparison has been performed between results obtained from the three analysed turbines for light and heavy LNG compositions. Results are shown in terms of both $\mathrm{gCO}_{2} / \mathrm{kWh}$ and $\mathrm{kgCO}_{2} / \mathrm{kgfuel}$ in figs. 4-5.
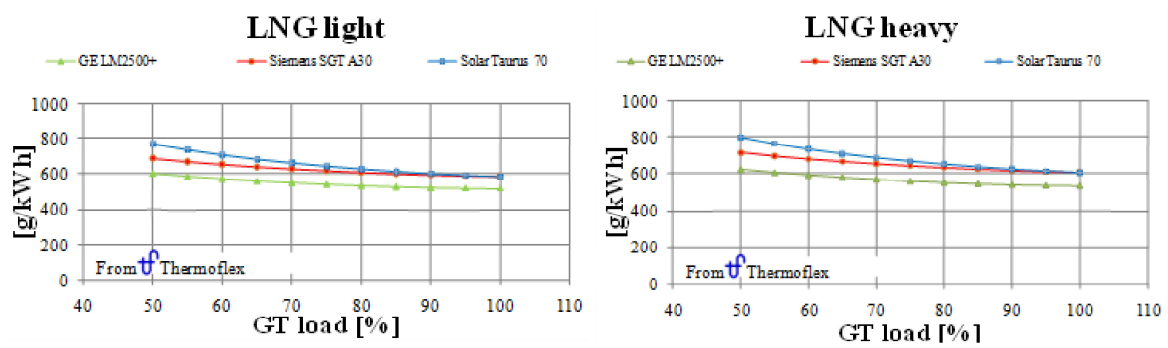

Fig. 4. $\mathrm{CO}_{2}$ emissions from GTs for LNG light (left) and LNG heavy (right). 

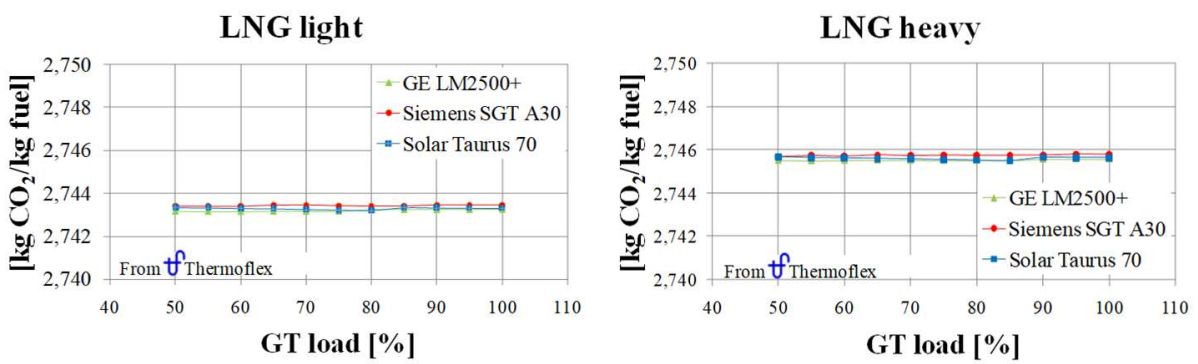

Fig. 5. $\mathrm{CO}_{2}$ emissions vs. fuel consumption from GTs for LNG light (left) and LNG heavy (right).

As expected, the $\mathrm{gCO}_{2} / \mathrm{kWh}$ values present a decreasing trend when the load increases, and the lowest are generated by the $\mathrm{LM} 2500+$ gas turbine. On the contrary, the $\mathrm{kgCO}_{2} / \mathrm{kgfuel}$ appear to be only slightly affected by the LNG composition.

\section{Conclusions}

Data contained in vendor datasheets and results obtained from software simulations show that present and future limits established for marine emissions are well compliant with the global regulation in force.

The advantage of introducing GTs in marine propulsion is backed up out of several considerations. The goal of a combined cycle is to achieve an increased work output for a given fuel supply. On account of such combined cycle designs, efficiencies are comparable to $2 \mathrm{~S} / 4 \mathrm{~S}$ diesel engines' ones. Large reciprocating engines furthermore suffer from large weight and dimensions; on the contrary, GTs prime movers are smaller and lighter, and the global weight of propulsion, including combined cycle components, is reduced [1, 5-6]. Dual fuel reciprocating engines (fuelled by oil derivate and/or gas) benefit from high efficiencies, low sulphur emission, but increased amount of equipment, high installation and maintenance costs are a major concern.

The extremely poor content in sulphur contaminants, due to the liquefaction production process and contaminant abatement LNG is subjected to, grants the option of an alternative fuel virtually $\mathrm{SO}_{2} / \mathrm{SO}_{3}$ free, capable of matching compulsory obligations. Furthermore, the GT combustion technology, with steady-state and controlled flame temperature grants heavy reduction in $\mathrm{NO}_{\mathrm{x}}$ emission, easily matching nitrogen regulations for current marine engines.

Finally, due to the fact that $\mathrm{CO}_{2}$ emission evaluation is becoming a key factor in marine propulsion $[20,21]$, as well as in the vessel design operational stage (EEDI/ EEOI indexes), the choice of LNG (with an environmental advantageous $\mathrm{C}$ to $\mathrm{H}$ ratio, when compared to usual diesel or heavy oils) is an undoubtedly innovative step from the environmental protection and GHG reduction point of view.

\section{References}

1. F. Haglind, A review on the use of gas and steam turbine combined cyceles as prime movers for large ships, Energ. Convers. \& Manag., 49, Part I 3458-67, Part II 3468-75, Part III 3476-82 (2008)

2. B.N. Sanneman, Pioneering Gas Turbine-Electric System in Cruise Ships: a performance update, Mar. Tech., 41, 4, 161-166 (2004)

3. M. Altosole, G. Benvenuto, U. Campora, M. Laviola, A. Trucco, Waste heat recovery from marine gas turbine and diesel engines, Energies, 10, 718 (2017)

4. I. Arias Fernández, M. Romero Gómez, J. Romero Gómez, A.Á. Baaliña Insua, Review of propulsion systems on LNG carriers, Ren. and Sust. En. Rev., 67, 1395-1411 (2017)

5. A. Alvarez, M. J. Coleman e J. Ordonez, Ship weight reduction and efficiency enhancement through combined power cycles, Energy, 93, 521-533 (2015) 
6. L. Ellington, G. Mc Andrews, A. H. Mensonides and R. Tanwar, Gas turbine propulsion for LNG transports, in ASME Turbo Expo 2006 (2006)

7. D. Woodyard, Pounder's marine Diesel engines and gas turbines, Nutterworth-Heinemann (2009)

8. B. M. Ackermann, Modular gas turbine propulsors: a viable alternative for today's merchant fleet, Mar. tech., 40, 2, 106-125 (2003)

9. J.J. Corbett, H.W. Koehler, Updated emissions from ocean shipping, Journ. of Geoph. Res., 108, D20 (2003)

10. V. Eyring, H.W. Koehler, J. van Aardenne, A. Lauer, Emissions from international shipping: 1. The last 50 years, Journ. of Geoph. Res., 110, DI17305 (2005)

11. Reducing sulphur emission from ships - The impact of international regulations, Intern. Trans. Forum Policy Papers, 18, OECD Publishing (2016)

12. Direttiva 2016/802 del Parlamento europeo e del Consiglio Ue del 11 maggio 2016 - Riduzione del tenore di zolfo di alcuni combustibili liquidi (Gazz. Uff. 2a Serie Sp. Un. Eur. n. 55 del 21/07/2016)

13. Resol. MEPC.176(58), Amendments to the annex of the protocol of 1997 to amend the international convention for the prevention of pollution from ships, 1973, as modified by the protocol of 1978 relating thereto - Revised MARPOL Annex VI, (adopt. Oct. 10 $0^{\text {th }}$ 2008)

14. Resol. MEPC.177(58) - Annex 14, Amendments to the technical code on control of emission of nitrogen oxides from marine diesel engines - NOX Technical Code 2008, mepc 58/23/add.1 (adopt. Oct. $10^{\text {th }}$ 2008)

15. Resol. MEPC.184(59) - Annex 9, 2009 guidelines for exhaust gas cleaning systems, mepc 59/24/add.1 (adopt. Jul. 17 $7^{\text {th }} 2009$ )

16. Resol. MEPC.259(68) - Annex 1, 2015 guidelines for exhaust gas cleaning systems, mepc 68/21/add.1 (adopt. May $15^{\text {th }} 2015$ )

17. Regulatory Update - Overview of EPA's Emission Standards for Marine Engines, EPA Off. of Transp. and Air Qual., EPAEPA420-F-04-031 (2004)

18. Resol. MEPC. 308 (73), 2018 guidelines on the method of calculation of the attained energy efficiency design index (EEDI) for new ships, mepc 73/19/add.1 (adopt. Oct. 26 ${ }^{\text {th }}$ 2018)

19. Circ. MEPC.684, Guidelines for voluntary use of the ship energy efficiency operational indicator (EEOI), mepc.1/Circ.684 (adopt. Aug. 17 $7^{\text {th }}$ 2009)

20. Regol. (UE) 2015/757 del Parlam. Eur. e del Cons. del 29 apr. 2015 - Monitoraggio, la comunicazione e la verifica delle emissioni di anidride carbonica generate dal trasporto marittimo (G.U.C.E 19/05/2015, L. 123/55)

21. Regol. Deleg. (UE) 2016/2071 della Commiss. del 22 sett. 2016 - Modifica regolamento (UE) 2015/757 del parlamento europeo e del consiglio per quanto riguarda i metodi per il monitoraggio delle emissioni di anidride carbonica e le regole relative al monitoraggio delle altre informazioni pertinenti (G.U.C.E 26/11/2016, L. 320/1)

22. GE datasheets, Fast, Flexible Power Aeroderivative Product and Service Solutions, GE Power \& Water (2013)

23. Siemens datasheets, Siemens gas turbine portfolio (2018)

24. Solar Turb. Incorp. datasheets, Taurus 70 - Gas Turbine generator set, Solar Turbines Incorp. (2018)

25. E. Querol, B. Gonzalez-Regueral, J. García-Torrent, M.J. García-Martínez, Boil off gas (BOG) management in Spanish liquid natural gas (LNG) terminals, Appl. En. 87, 3384-92 (2010)

26. Technical Statement on Commercial Natural Gas in CNG and LNG Fueled Mobile Heavy-Duty Engine Applications, Truck \& Engine Manuf. Assoc., Chicago Illinois (2014)

27. $L N G$ and gas quality and measurement manual for $L N G$ carriers calling at terminal-offshore $L N G$ TOSCANA S.p.A. (OLT), LNG and Gas Qual. and Meas. Man., OLT s.p.a., rev.06 (2017)

28. S. Johannesson, M. Rey, X. Ribas $L N G$ Blue Corridors - Gas quality, DG MOVE $7^{\text {th }}$ framework programme GC.SST.2012.2-3 GA NO. 321592, Eur. Comm. (2014)

29. THERMOFLEX ${ }^{\circledR}$ licence v28.2 by Thermoflow Inc. (2019)

30. S. R. Turns, An Introduction to Combustion. Concepts and Applications, 3rd Edition, McGraw Hill, (2012)

31. C. Olikara, G. L. Borman, A Computer Program for Calculating Properties of Equilibrium Combustion Products with Some Applications to I. C. Engines, SAE Paper 750468 (1975)

32. G. A. Lavoie, J. B. Heywood, J. C. Keck, Experimental and theoretical study of nitric oxide formation in internal combustion engines, Combustion science and technology, 1, 4, 313-326 (1970) 